\title{
Terapia ocupacional e tecnologia assistiva: reflexóes sobre a experiência em consultoria colaborativa escolar ${ }^{1}$
}

\author{
Luciana Ramos Baleotti, Mariana Dutra Zafani \\ Departamento de Fisioterapia e Terapia Ocupacional, Universidade Estadual Paulista - UNESP, Marília, SP, Brasil.
}

\begin{abstract}
Resumo: Trata-se da apresentação de reflexões pautadas na experiência desenvolvida junto ao projeto Tecnologia Assistiva na Inclusão do Aluno com Deficiência Física: Recursos e Procedimentos, em desenvolvimento desde o ano de 2009. Este projeto visa contribuir para o processo de inclusão escolar de alunos com deficiência física inseridos em classes regulares da educação infantil do município de Marília-SP, por meio da colaboração entre saúde e educação. A colaboração dos profissionais da saúde se dá por meio da implementação dos recursos da Tecnologia Assistiva através da Consultoria Colaborativa Escolar. Este projeto foi desenvolvido em seis diferentes estágios: i) Ganhar entrada e estabelecer objetivos da equipe; ii) Identificação do Problema; iii) Intervenções/Recomendações; iv) Implementação; v) Avaliação, e vi) Prosseguimento. Através deste modelo de trabalho, nós procuramos a inserção do terapeuta ocupacional no ambiente escolar. Este projeto tem evidenciado a importância de se ter o terapeuta ocupacional como parte da equipe no ambiente escolar e a importância do trabalho colaborativo entre as áreas da saúde e da educação.
\end{abstract}

Palavras-chave: Terapia Ocupacional, Tecnologia Assistiva, Deficiência Física, Ambiente.

\section{Occupational Therapy and assistive technology: thoughts about the experience with collaborative school consulting}

\begin{abstract}
This study presents thoughts and ideas based on the experience developed in the project entitled Assistive Technology for Inclusion of Students with Physical Disorders: Resources and Procedures, in development since 2009. This project aims to help in the process of school inclusion of students with physical disorder in Early Childhood Education in the city of Marilia, Brazil, through the collaboration between Health and Education departments. Health professionals contribute through the implementation of the Assistive Technology by means of school consulting. The project has been developed in six different stages, namely: Gaining access and establishing goals for the team; Identifying the problem; Interventions/Recommendations; Implementation; Evaluation and further actions. This working model, seeks to insert occupational therapy in the school environment. This project showed the importance of occupational therapists as team members in school settings, and the importance of a collaborative work between Education and Health departments.
\end{abstract}

Keywords: Occupational Therapy, Assistive Technology, Physical Disability, Environment.

\footnotetext{
Autor para correspondência: Luciana Ramos Baleotti, Faculdade de Filosofia e Ciências, Universidade Estadual Paulista, Campus de Marília, Avenida Hygino Muzzi Filho, 737, Campus Universitário, CP 181, Marília, SP, Brasil, e-mail: baleotti@marilia.unesp.br

Recebido em Maio 4, 2016; 1ª Revisão em Ago. 31, 2016; Aceito em Nov. 17, 2016.
} 


\section{Introdução}

Os preceitos filosóficos da educação inclusiva têm evidenciado a colaboração entre profissionais da escola, família e profissionais de outras áreas de conhecimento como relevante para a resolução de problemas dos alunos e de desenvolvimento pessoal e profissional de todos os envolvidos (MENDES, 2006). Os profissionais da área da saúde são importantes no processo de colaboração, em virtude de poderem auxiliar na identificação das necessidades educacionais especiais dos alunos e na tomada de decisóes quanto às açóes que favoreçam o processo de ensino e aprendizagem (BRASIL, 2001). Mais recentemente, a articulação entre profissionais da saúde e da educação tem sido discutida com base no conceito de intersetorialidade, o qual induz a relaçóes não hierarquizantes entre esses profissionais e preconiza o estabelecimento de parcerias úteis e espaços compartilhados de decisóes, visando à atenção integral aos sujeitos (BRASIL, 2009b; CASTRO; REGATTIERI, 2009). Sob essa perspectiva, a parceria pode ser subsidiada por uma participação colaborativa e integrativa entre os profissionais, de forma que as ações intersetoriais se constituam como importante elemento para a promoção da aprendizagem, no contexto educacional (GIROTO; SILVA; SANTANA, 2014).

A colaboração dos profissionais da saúde pode ser entendida como um recurso adicional com que a escola pode contar para viabilizar estratégias educacionais inclusivas, que favoreçam o desenvolvimento da criança em todas as suas necessidades, sejam estas físicas, sensoriais, intelectuais e/ou sociais.

A colaboraçáo pode se efetivar por meio da Consultoria Colaborativa Escolar, a qual é definida como um processo no qual o consultor trabalha numa relação igualitária e não hierárquica com o consultante. Busca-se reunir os esforços de ambos para a tomada de decisóes e o planejamento de intervençôes que melhor atendam às necessidades dos alunos (KAWPWIRTH, 2003).

A consultoria colaborativa vem sendo considerada como um dos elementos para uma inclusão escolar bem sucedida, sendo relevante no desenvolvimento de intervençôes frente às dificuldades de aprendizagem do aluno e "[...] no sentido de unir forças para realizar conquistas político-sociais” (ARAÚJO; ALMEIDA, 2014, p. 343).

Apresenta-se como um viés importante para a atuaçáo dos(as) profissionais especializados(as) da área da saúde no campo da educação, devido a esses atores apresentarem competências e habilidades profissionais que podem auxiliar o exercício profissional dos(as) professores(as) (CALHEIROS; DOUNIS, 2015, p. 113).

Um dos profissionais que pode atuar como consultor escolar é o terapeuta ocupacional, sendo que este atua no sentido de proporcionar um sistema de prestação de serviços que busque a efetiva participação e a inclusão de alunos com necessidades educacionais especiais (ZANATA, 2005).

Gebrael e Martinez (2011) elaboraram, implementaram e avaliaram um programa (PRÓ-AVD) individualizado de consultoria colaborativa em terapia ocupacional para professores da Educação Infantil regular, com o intuito de expandir o repertório de recursos e estratégias dos professores para favorecer a independência de crianças pré-escolares com baixa visão nas atividades de higiene e alimentação. Dentre os resultados do estudo, destaca-se o aumento de ocorrências de atitudes das professoras que incentivavam a independência do aluno na realização das $\mathrm{AVDs}$ (higiene e alimentação). Além disso, as autoras reforçam a possibilidade de que, após a participação no Programa, o professor possa estender seus conhecimentos e o repertório de estratégias para ajudar outros alunos com baixa visão, além da possibilidade de que os benefícios advindos do Programa PRÓ-AVD se estendam para a vida escolar do aluno como um todo, colaborando com o processo de inclusão escolar.

$\mathrm{O}$ advento da educação inclusiva fortaleceu ainda mais a atuação dos terapeutas ocupacionais diretamente no contexto escolar. A atuação nesse contexto é completamente diferente da atuação na clínica e deve estar voltada para os ambientes físico e social, que juntos interagem e contribuem para a efetiva participação do aluno com deficiência. A escola é um dos contextos concretos e significativos da vida de qualquer criança. Assim, se não estiver ajustada para atender às limitaçốes impostas pela condição da deficiência, pode interferir negativamente na autonomia e na participação social da criança.

A adequação do ambiente físico, dos recursos pedagógicos e dos materiais escolares representa uma das possibilidades importantes no contexto da educaçáo inclusiva, e vai ao encontro das proposiçôes estabelecidas no documento Política Nacional de Educaçáo Especial, na perspectiva da Educaçáo Inclusiva. Neste documento, considera-se

[...] pessoa com deficiência aquela que tem impedimentos de longo prazo, de natureza física, mental ou sensorial que, em interaçáo com diversas barreiras, podem ter restringida 
sua participação plena e efetiva na escola e na sociedade (BRASIL, 2007, p. 9).

Com base nessa conceituação, a deficiência é uma das características do indivíduo atrelada às condiçóes de relação entre a própria deficiência e o contexto social no qual este indivíduo está inserido. Nesse sentido, um aluno com deficiência física, se não tiver um ambiente adequado que minimize a dificuldade de acessibilidade decorrente da deficiência, ou um meio social com atitudes acolhedoras, a relação entre o que é individual e social deixa de existir, na medida em que condiçóes extrínsecas ao indivíduo contribuem para o processo de exclusão mediante as inadequaçóes inerentes ao meio físico e/ou social (BALEOTTI, 2006).

Muitas vezes, observam-se discrepâncias entre essas condiçóes de relação. As demandas ambientais inadequadas, em muitos casos, colaboram para a falta de autonomia e participação do sujeito. $\mathrm{O}$ conhecimento e o acesso do professor aos recursos da TA que possam, em algum grau, diminuir ou eliminar essa discrepância se fazem pertinentes no contexto educacional do aluno com deficiência.

Tecnologia Assistiva é uma área do conhecimento, de característica interdisciplinar, que engloba produtos, recursos, metodologias, estratégias, práticas e serviços que objetivam promover a funcionalidade, relacionada à atividade $\mathrm{e}$ participação de pessoas com deficiência, incapacidades ou mobilidade reduzida, visando sua autonomia, independência, qualidade de vida e inclusão social (BRASIL, 2009a, p. 3).

Pensando-se nos aspectos que permeiam a proposta da educação inclusiva e da consultoria colaborativa, o terapeuta ocupacional é um dos profissionais capazes de atuar com questóes relacionadas às condiçóes de acessibilidade e utilização de tecnologias que visem ao desempenho e à funcionalidade do sujeito, nos diversos contextos de convivência (MARINS; EMMEL, 2011).

A implementação dos recursos de TA, por meio da Consultoria Colaborativa, pode facilitar a inserção desse profissional no espaço escolar para a aproximação com os educadores, com vistas à troca e construção coletiva de saberes e práticas direcionadas para a melhoria da qualidade educacional dos alunos com deficiência.

É nessa direção que se configura a proposição deste projeto, o qual visa contribuir para o processo de inclusão escolar de alunos com deficiência física inseridos em classes regulares da educação infantil do município de Marília-SP, por meio da colaboraçáo entre saúde e educação.

\section{A Proposta}

Apresenta-se a experiência de um projeto de extensão desenvolvido por meio da cooperação entre a Universidade e o Centro Escola Municipal de Atendimento Educacional Especializado (CEMAEE), vinculado à Secretaria Municipal de Educação de Marília-SP. Esse projeto iniciou-se em 2009 e conta com o financiamento da Pró-Reitoria de Extensão Universitária - PROEX, da Universidade Estadual Paulista - Unesp.

O CEMAEE é responsável pelo acompanhamento pedagógico de alunos com deficiência, englobando aqueles com Transtornos Globais do Desenvolvimento e Altas Habilidades/Superdotação, matriculados nas escolas da rede municipal de ensino de Marília.

Ressalta-se que, atualmente, de acordo com o censo/2016 e a PRODESP - Companhia de Processamento de Dados do Estado de São Paulo, registram-se 220 alunos com necessidades especiais matriculados na Educação Básica das escolas municipais de Marília. Destes, 78 apresentam deficiência física, dos quais 37 estão inseridos em escolas da Educação Infantil, população-alvo deste projeto. O município de Marília conta com 14 salas de recursos multifuncionais e o atendimento especializado nessas salas é feito por 32 professores, sendo alguns especialistas na área da Educação Especial e outros com cursos de longa duração na mesma área.

Registra-se que esse projeto contempla açóes colaborativas com os professores das salas regulares, nas quais os alunos com deficiência física estão inseridos, e com os professores das salas de recursos multifuncionais.

Com o objetivo de contemplar a interface e de constituir uma proposta de complementariedade de conhecimentos e não de hierarquização, o projeto foi desenvolvido em estágios de intervenção que consideram, sobretudo, a demanda e a necessidade expostas pelos professores que atuam diretamente com alunos com deficiência física, no contexto educacional inclusivo. A forma de aproximação com esses professores está descrita nos estágios de intervenção subsequentes.

Os seis estágios no processo de consultoria colaborativa estabelecidos por Idol, Nevin e PaolucciWhitcomb (2000 apud ARAÚJO; ALMEIDA, 2014, p. 346-347) nortearam as ações desenvolvidas nesse projeto. Salienta-se que, neste trabalho, foi adotada a terminologia utilizada por esses autores para a 
definição dos estágios de intervenção, os quais se encontram descritos a seguir.

\subsection{Primeiro Estágio: ganhar entrada e estabelecer objetivos da equipe}

No início de cada ano letivo, o CEMAEE fornece à coordenadora desse projeto a lista da PRODESP, que contém informaçóes relativas aos alunos com necessidades especiais devidamente cadastrados e matriculados nas escolas municipais de Marília. Dessa forma, são identificados os professores que serão convidados a participar do projeto. Ressalta-se que são convidados aqueles que atendem ao critério de os alunos com deficiência física receberem atendimento no Estágio Supervisionado de Terapia Ocupacional em Neuropediatria, na clínica-escola da Unesp, como uma das formas de se efetivar ainda mais a parceria entre a Universidade e o CEMAEE. Dessa forma, esse projeto tem atendido anualmente uma média de 15 alunos com deficiência física e seus professores. Este critério possibilita também uma maior articulação entre as atividades de ensino, pesquisa e extensão universitária, com vistas ao favorecimento do processo educativo de um maior número de alunos da graduação e não apenas para os alunos bolsistas vinculados ao projeto. Com isso, há a possibilidade de esses alunos compreenderem a extensão universitária como uma prática de interação entre a universidade e a comunidade externa. Prática esta que busca, além do favorecimento do processo educativo, o atendimento de uma demanda socioeducacional importante para a terapia ocupacional.

As ações iniciam-se com visitas escolares com os objetivos de apresentar a proposta do projeto para cada unidade escolar, solicitar autorizaçáo para o seu desenvolvimento nas escolas e convidar os professores para participarem do mesmo. Após o aceite, realiza-se uma conversa informal a fim de dialogar sobre a colaboração da terapia ocupacional no contexto escolar, especificamente junto ao aluno com deficiência física, com ênfase ao uso de recursos da TA. Além disso, as responsabilidades e os papéis de cada um dos envolvidos, terapeuta ocupacional e professor, são discutidos, deixando-se claro que as ações a serem desenvolvidas demandarão planejamento conjunto.

\subsection{Segundo Estágio: identificação do problema}

Após o primeiro contato, é feito um levantamento inicial das necessidades vivenciadas pelo professor em contexto educacional, com o intuito de estabelecer vínculo para o compartilhamento de ideias e a construção coletiva de saberes que possam atender às suas reais necessidades. $\mathrm{O}$ modelo de consultoria colaborativa prevê uma relação mais abrangente, em que profissionais da saúde e da educação são coautores e corresponsáveis no compartilhamento de conhecimentos teórico-práticos (GIROTO; SILVA; SANTANA, 2014). Assim, o vínculo se estabelece na medida em que as açóes da terapia ocupacional são pensadas a partir do levantamento das necessidades do professor, sujeito que vivencia as dificuldades que se apresentam no cotidiano educacional.

O terapeuta ocupacional atua, portanto, como um facilitador, definindo, junto com o consultado, os objetivos a serem alcançados (TREVISAN; DELLA BARBA, 2012).

Esse levantamento inicial é feito por meio de entrevista com o professor, a fim de identificar elementos que o mesmo julga que necessitam da interlocuçáo com o terapeuta ocupacional, para a resoluçáo dos problemas que emergem no cotidiano educacional. Nessa entrevista, investigam-se os seguintes aspectos: repertório de estratégias do professor em relaçáo ao ensino do aluno com deficiência física; as implicaçôes da deficiência e das condiçóes do meio para o processo de ensino e aprendizagem do aluno; o conhecimento sobre a problemática da criança com deficiência física incluída em sua sala de aula; o entendimento sobre o significado da educação inclusiva, e outros aspectos que o professor identifica como importantes e que devem ser problematizados mutuamente.

Tratando-se de alunos com deficiência física, a implementação de recursos didáticos e equipamentos pode fazer-se necessária, no sentido de promover a participação dos mesmos nas atividades escolares (BRASIL, 2006). A TA na escola configura-se como uma possibilidade para resolver problemas funcionais do aluno com deficiência física, criando novas alternativas para a leitura, a escrita e as brincadeiras, e para a utilização dos materiais escolares, dentre outras atividades, valorizando, sobretudo, suas habilidades (BERSCH, 2007). Talvez, por esse motivo e pelo despreparo dos professores para a sua implementação em sala de aula, as questóes relacionadas ao uso da TA evidenciam-se com frequência na fala dos professores que fazem parte desse projeto.

Mediante isso, as reflexôes se ampliam na medida em que buscamos discutir conjuntamente a finalidade do recurso da TA, ou seja, qual o significado de um mobiliário ou de um material escolar adaptado no contexto da educaçáo inclusiva. Entende-se que o recurso não deve representar um fim em si mesmo, mas um meio para promover, de fato, o processo 
de inclusão escolar, como preconizam os preceitos filosóficos que o fundamentam. Giroto, Poker e Omote (2012) ressaltam que a TA pode colaborar na mediação entre o aluno e o conhecimento; no entanto, esta, por si só, não garante a escolarização do aluno.

Para complementar a identificação de situações escolares que o professor julga como pertinentes para o compartilhamento de reflexóes e a busca de soluçôes, realizam-se registros, por meio de procedimento de filmagem da criança com deficiência física durante as atividades desenvolvidas no contexto escolar. A filmagem acontece em situaçóes de sala de aula, de recreio, de parque, de alimentaçáo, e de outras desenvolvidas no contexto da Educação Infantil. Busca-se obter informaçóes relativas às habilidades e/ou dificuldades dos alunos com deficiência física que impactam no desempenho de atividades, a fim de prever os recursos da TA que poderáo minimizar a dificuldade, implementar a função e favorecer a participação deles nas atividades escolares. Além de registrar tais informaçôes, o procedimento de filmagem possibilita o registro das interaçóes sociais que se efetivam em torno do aluno com deficiência física e das estratégias de ensino adotadas pelo professor, as quais também compóem as discussôes nos encontros presenciais.

\subsection{Terceiro Estágio: intervenções/ recomendações}

Neste estágio, realiza-se a análise dos dados advindos da entrevista e dos registros de filmagem.

São agendados encontros grupais com os professores das salas regulares e do AEE, objetivando a reflexão dos elementos que surgiram na entrevista inicial. Nesse momento, procura-se entender a aproximação entre a terapia ocupacional e a educação, com foco no processo de ensino e aprendizagem do aluno com deficiência física, ou seja, em quais aspectos a interdisciplinaridade pode se efetivar e em quais, há a necessidade da interlocução com profissionais de outras áreas de conhecimento. Afinal, às vezes, o professor da sala regular menciona elementos, tais como comportamentais, de comunicação ou de interações familiares, que requerem a interlocução com psicólogos, fonoaudiólogos, e o auxílio mais efetivo do professor do AEE, a fim de assegurar a resolução dos problemas de maneira mais eficaz.

A proposição é a de buscar estratégias conjuntas para a resolução dos problemas, mas a implementação das mesmas é de responsabilidade do professor da sala regular, com o apoio do professor do AEE, conforme preconizam as legislaçóes vigentes (BRASIL, 2010, 2011). No entanto, essa não é uma tarefa fácil, pois alguns professores ainda desenvolvem uma relação de dependência com o profissional da saúde/consultor. Com este projeto, busca-se empoderá-los, a fim de que tenham condiçôes de definir objetivos, metas e estratégias, mesmo na ausência do terapeuta ocupacional.

Com relação aos dados advindos dos procedimentos de filmagem, estes são analisados juntamente com os professores das salas regulares e do AEE. Tal análise se dá mediante referenciais teóricos da área da terapia ocupacional, no que se refere ao processo de análise do desempenho ocupacional (AMERICAN..., 2015). Procura-se discutir com os professores a relevância de a análise de habilidades de desempenho do aluno ser feita mediante a observaçáo deste aluno durante a realização de atividades desenvolvidas no contexto escolar. A partir disso, incentiva-se a percepção acerca da existência e/ou da inexistência da relação entre as demandas do aluno, da tarefa e do ambiente, destacando que tal percepção possibilitará sugerir atividades educacionais e recursos pedagógicos mais adequados aos alunos com deficiência física.

Esses momentos de reflexôes possibilitam identificar, com maior clareza, o papel de cada um dos profissionais, sobretudo do terapeuta ocupacional, no âmbito do processo educacional inclusivo do aluno com deficiência física, alvo deste projeto. Além disso, possibilita evidenciar aos professores e aos graduandos de Terapia Ocupacional que a existência da condição de deficiência física nem sempre tem relaçáo direta com o uso de recursos de TA. É necessário desenvolver o entendimento de que a "[...] deficiência se reporta às condiçóes orgânicas do indivíduo, que podem resultar em uma necessidade educacional especial, porém não obrigatoriamente" (GLAT; PLETSCH; FONTES, 2007, p. 349). A necessidade educacional especial é "[...] um produto da interaçáo do aluno com o contexto escolar em que a aprendizagem deverá se dar" (GLAT; PLETSCH; FONTES, 2007, p. 349).

\subsection{Quarto Estágio: implementação das recomendações}

Como um dos objetivos deste projeto de extensão é o de possibilitar a aproximação da terapia ocupacional com a educação, tendo a TA como um meio facilitador para essa aproximação, este estágio tem a finalidade de, quando necessário, propiciar aos alunos com deficiência física e seus professores, recursos da TA como uma das possibilidades para 
o ensino inclusivo e a participação desses alunos no contexto escolar.

É fato que nem todos os alunos com deficiência física necessitarão de recursos de TA. Entretanto, existem aqueles que possuem incapacidades, impostas pela condição da deficiência, que irão se manifestar na interaçáo entre as demandas do meio e as características deles. Assim, a disponibilização dos recursos para esses alunos tem o grande mérito de deslocar a atençáo do professor para o meio, ao evidenciar que a atividade e/ou os materiais escolares, se oferecidos da forma convencional para um determinado aluno com deficiência física, podem limitar o desempenho desse aluno e, consequentemente, contribuir para uma avaliação pedagógica equivocada, ou seja, centrada apenas no aluno e não na relação deste com o meio.

\subsection{Quinto e Sexto Estágios: avaliação e prosseguimento}

Por meio de um protocolo ${ }^{2}$ de avaliação e acompanhamento da eficácia do uso da TA, são feitas reuniōes quinzenais com o professor com o objetivo de discutir e avaliar conjuntamente o quanto os recursos utilizados pelo aluno com deficiência física propiciam o acesso ao currículo e à participação nas atividades desenvolvidas no contexto escolar. O suporte oferecido à escola não deve limitar-se somente às fases de implementação do recuso de TA, mas deve contemplar "[...] as fases posteriores de acompanhamento, ajustes, personalização e revisões" (GALVÃO FILHO, 2009, p. 155). Tal seguimento é fundamental não apenas para que a aplicação das soluçôes encontradas seja bem sucedida, mas também para que não aconteça abandono da TA usada (GALVÂO FILHO, 2009).

A percepção do professor em relação ao uso do recurso de TA fornece dados importantes referentes à maneira como eles estáo sendo implementados $\mathrm{e}$ usados no ambiente escolar (ALVES; MATSUKURA, 2012). É essencial considerar as necessidades e opiniōes das pessoas que estão diretamente envolvidas no contexto em que o recurso de TA encontra-se inserido (ALVES, 2009).

No estudo desenvolvido por Alves e Matsukura (2012), verificou-se que os professores citaram os critérios que consideravam necessários para um recurso de TA eficiente, sendo estes: praticidade, motivação e interesse do usuário, e a especificidade. Segundo as autoras, esse dado reforça que a eficiência dos recursos de TA está atrelada aos resultados proporcionados ao seu usuário e ao contexto, e não se deve apenas à sua presença em sala de aula. $\mathrm{O}$ recurso de TA não é autossuficiente, o professor deve mediar $\mathrm{e}$ acompanhar o seu uso, a fim de verificar se está atendendo às necessidade da criança de maneira eficiente (REIS; FLORES, 2014).

Para alguns alunos com deficiência física, a interação na atividade ocorre a partir do momento em que lhe são proporcionadas condiçốes materiais para isso, o que pode favorecer também a interação social com os demais colegas da escola (PASCULLI; BALEOTTI; OMOTE, 2012). Nessa perspectiva, o foco não recai sobre o recurso em si, mas sim sobre a possibilidade de investigar a eficácia do mesmo para a provisão de atividades adequadas, que favoreçam a participação e a autonomia do aluno com deficiência no ambiente escolar.

Além disso, essa forma de coletar informaçóes junto ao professor tem possibilitado a cooperação entre os envolvidos e a revisão mútua de situaçóes que permitem o avanço no processo de amadurecimento e a aquisiçáo de conhecimentos por parte de todos os alunos.

O protocolo possibilita identificar também a satisfação do professor em relaçáo ao uso da TA. A análise da satisfação se faz necessária por estar atrelada ao uso de modo regular ou ao abandono do recurso. É importante que tanto o aluno, que é o usuário do recurso, quanto o professor, que irá acompanhar a sua implementaçáo e funcionalidade, estejam satisfeitos com o seu uso.

Costa et al. (2015) identificaram uma série de fatores que estáo relacionados ao abandono do recurso de TA, dentre os quais, podem-se citar: dor, dificuldade de uso, insatisfação, desconforto, preferência por outro recurso de TA ou utilização de capacidades remanescentes.

O recurso de TA deve promover a participação do aluno nas atividades escolares com conforto e segurança; do contrário, seu uso poderá gerar descontentamento.

A partir dessa discussão, é possível verificar a adequação ou não do recurso com vistas a atender com eficácia a necessidade do professor e do aluno.

Com esta ação, evidencia-se uma das possibilidades da terapia ocupacional em subsidiar o trabalho do professor e fortalece-se a aproximação entre as áreas da saúde e da educação, fundamentada em uma prática que busca favorecer as interaçóes entre os profissionais dessas duas áreas de conhecimento, ao mesmo tempo em que possibilita o desenvolvimento da cooperação entre esses profissionais. 


\section{Conclusão}

Este projeto tem possibilitado a aproximação e o estabelecimento de vínculo entre o terapeuta ocupacional e educadores. Envolve a proposta do uso da TA como forma de evidenciar uma das possibilidades do terapeuta ocupacional atuar, como consultor no campo da educação, bem como compor a equipe de profissionais desse campo.

A opção por centrar as açóes no processo de escolarização do aluno com deficiência física, com foco na TA, propiciou-nos conhecer a multiplicidade de demandas levantadas pelo professor e de perfis de alunos com deficiência física inseridos em classes regulares da educação infantil do município de Marília. Em muitos casos, as demandas se assemelham, quando se cita a necessidade de adaptação de recursos pedagógicos e de adequação de mobiliário e de materiais escolares. Em outros casos, as demandas se distanciam, como em questôes relacionadas mais especificamente aos problemas de ordem comportamental e de cognição.

Ressalta-se a importância de propostas de projetos interdisciplinares, como uma forma de estabelecer conexão entre as áreas, em que saúde e educação se vinculem para somar esforços para o oferecimento de suporte à inclusão e à participação efetiva de alunos com deficiências em contextos educacionais inclusivos.

\section{Referências}

ALVES, A. C. J. A tecnologia assistiva como recurso à inclusão escolar de crianças com paralisia cerebral. 2009. 168 f. Dissertaçấo (Mestrado em Educação Especial) - Universidade Federal de São Carlos, São Carlos, 2009.

ALVES, A. C. J.; MATSUKURA, T. S. O uso de recursos de tecnologia assistiva por crianças com deficiência física na escola regular: a percepção dos professores. $\mathrm{Ca}$ dernos de Terapia Ocupacional da UFSCar, São Carlos, v. 20, n. 3, p. 381-392, 2012.

AMERICAN OCCUPATIONAL THERAPY ASSOCIATION - AOTA. Occupational therapy practice framework: domain and process. Revista de Terapia Ocupacional da Universidade de São Paulo, Sáo Paulo, v. 26, p. 1-49, 2015. Edição Especial.

ARAÚJO, S. L. S.; ALMEIDA, M. A. Contribuiçóes da consultoria colaborativa para a inclusão de pessoas com deficiência intelectual. Revista de Educação Especial, Santa Maria, v. 27, n. 49, p. 341-351, 2014.

BALEOTTI, L. R. Um estudo do ambiente educacional inclusivo: descrição das atitudes sociais em relação à inclusão e das relaçôes interpessoais. 2006. 183 f. Tese (Doutorado em Educação) - Universidade Estadual Paulista, Marília, 2006.
BALEOTTI, L. R.; OMOTE, S. A concepção de deficiência em discussáo: ponto de vista de docentes de Terapia Ocupacional. Cadernos de Terapia Ocupacional da UFSCar, São Carlos, v. 22, n. 1, p. 71-78, 2014.

BERSCH, R. Tecnologia assistiva. In: SCHIRMER, C. R. et al. Atendimento educacional especializado: deficiência física. Brasília: MEC, 2007.

BRASIL. Conselho Nacional de Educação. Resolução $\mathrm{n}^{\circ}$ 2, de 11 de setembro de 2001. Institui as Diretrizes Nacionais para a Educação Especial na Educação Básica. Diário Oficial [da] República Federativa do Brasil, Brasília, DF, 14 set. 2001.

BRASIL. Ministério da Educação. Secretaria de Educação Especial. Sala de recursos multifuncionais: espaços para o Atendimento Educacional Especializado. Brasília: MEC, 2006.

BRASIL. Ministério da Educação. Secretaria de Educação Especial. Política Nacional de Educação Especial na perspectiva da Educação Inclusiva. Brasília: MEC, 2007.

BRASIL. Subcretaria Nacional de Promoção dos Direitos da Pessoa com Deficiência. Comitê de Ajudas Técnicas. Tecnologia assistiva. Brasília: CORDE, 2009a.

BRASIL. Ministério da Saúde. O SUS de A a Z: garantindo saúde nos municípios. Brasília: MS, 2009b.

BRASIL. Ministério da Educação. Conselho Nacional de Educação. Câmara de Educação Básica. Resolução no 4, de 13 de julho de 2010. Define Diretrizes Curriculares Nacionais Gerais para a Educação Básica. Diário Oficial [da] República Federativa do Brasil, Brasília, DF, 13 jul. 2010. Disponível em: <http://portal.mec.gov.br/ dmdocuments/rceb004_10.pdf>. Acesso em: $10 \mathrm{dez}$. 2014.

BRASIL. Ministério da Educaçáo. Decreto n ${ }^{\circ} 7.611$, de 17 de novembro de 2011. Dispóe sobre a educação especial, o atendimento educacional especializado e dá outras providências. Diário Oficial [da] República Federativa do Brasil, Brasília, DF, 18 nov. 2011. Disponível em: <http:// www.planalto.gov.br/ccivil_03/_ato2011-2014/2011/decreto/d7611.htm>. Acesso em: $10 \mathrm{dez} .2014$.

CALHEIROS, D. S.; DOUNIS, A. B. A formação do terapeuta ocupacional na perspectiva da educaçáo inclusiva. Educa - Revista Multidisciplinar em Educação, Porto Velho, v. 2, n. 4, p. 110- 129, 2015.

CASTRO, J. M.; REGATTIERI, M. (Org.). Interaçaao escola-família: subsídios para práticas escolares. Brasília: UNESCO, 2009.

COSTA, C. R. et al. Dispositivos de tecnologia assistiva: fatores relacionados ao abandono. Cadernos de Terapia Ocupacional da UFSCar, São Carlos, v. 23, n. 3, p. 611624, 2015.

GALVÃO FILHO, T. A. Tecnologia assistiva para uma escola inclusiva [recurso eletrônico]: apropriação, demanda e perspectivas. 2009. $346 \mathrm{f}$. Tese (Doutorado em Educação) - Universidade Federal da Bahia, Salvador, 2009.

GEBRAEL, T. L. R.; MARTINEZ, C. M. S. Consultoria colaborativa em terapia ocupacional para profes- 
sores de crianças pré-escolares com baixa visão. Revista Brasileira de Educação Especial, Marília, v. 17, n. 1, p. 101-120, 2011.

GLAT, R.; PLETSCH, M. D.; FONTES, R. S. Educação inclusiva \& educação especial: propostas que se complementam no contexto da escola aberta à diversidade. Educação, Santa Maria, v. 32, n. 2, p. 343-356, 2007.

GIROTO, C. R. M.; POKER, R. B.; OMOTE, S. Educação Especial, formação de professores e o uso das tecnologias de informação e comunicação: a construção de práticas pedagógicas inclusivas. In: GIROTO, C. R. M.; POKER, R. B.; OMOTE, S. (Org.). As tecnologias nas práticas pedagógicas inclusivas. Marília: Oficina Universitária; São Paulo: Cultura Acadêmica, 2012. p. 11-24.

GIROTO, C. R. M.; SILVA, A. P. B. V.; SANTANA, A. P. O. Saúde, educação e Educação Especial: princípios e paradigmas norteadores das práticas em saúde no contexto educacional inclusivo. In: GIROTO, C. R. M. et al. (Ed.). Servicios de apoyo em Educación Especial: uma mirada desde diferentes realidades. Alcalá de Henares: Universidad de Acalá, 2014. p. 105-125.

KAWPWIRTH, T. J. Collaborative consultation in the schools: effective practices for students with learning and behavior problems. New Jersey: Merril Prentice Hall, 2003.

MARINS, S. C. F.; EMMEL, M. L. G. Formação do terapeuta ocupcional: acessibilidade e tecnologias. $\mathrm{Ca}$ - dernos de Terapia Ocupacional da UFSCar, São Carlos, v. 19, n. 1, p. 37-52, 2011.

MENDES, E. G. A radicalização do debate sobre inclusão escolar no Brasil. Revista Brasileira de Educação, Rio de Janeiro, v. 11, n. 33, p. 387-405, 2006.

ORGANIZAÇÃO MUNDIAL DA SAÚDE - OMS. Classificação internacional de funcionalidade, incapacidade e saúde. São Paulo: Universidade de São Paulo, 2008.

PASCUlli, A. G.; BALEOTTI, L. R.; OMOTE, S. Interação de um aluno com paralisia cerebral com colegas de classe durante atividades lúdicas. Revista Brasileira de Educação Especial, Marília, v. 18, n. 4, p. 587-600, 2012.

REIS, C. V.; FLORES, M. M. L. Tecnologia assistiva na perspectiva das professoras de atendimento educacional especializado no sudeste goiano. Revista Intersaberes, Araraquara, v. 9, n. 18, p. 255-286, 2014.

TREVISAN, J. G.; DELLA BARBA, P. C. S. Reflexões acerca da atuaçáo do terapeuta ocupacional no processo de inclusão escolar de crianças com necessidades educacionais especiais. Cadernos de Terapia Ocupacional da UFSCar, São Carlos, v. 20, n. 1, p. 89-94, 2012.

ZANATA, E. M. Práticas pedagógicas inclusivas para alunos surdos numa Perspectiva colaborativa. 2005. $198 \mathrm{f}$. Tese (Doutorado em Educação Especial) - Universidade Federal de São Carlos, São Carlos, 2005.

\section{Contribuição dos Autores}

Todas as autoras contribuíram igualmente em todas as fases do estudo. Todos os autores aprovaram a versão final do texto.

\section{Fonte de Financiamento}

Pró-Reitoria de Extensão Universitária - PROEX da Universidade Estadual Paulista.

\section{Notas}

${ }^{1}$ Trata-se de um relato de experiência referente às atividades desenvolvidas no projeto de extensão e pesquisa Tecnologia Assistiva na Inclusão do Aluno com Disfunção Física: Recursos e Procedimentos.

${ }^{2}$ Protocolo de coleta de dados em fase final de elaboração, sendo desenvolvido pelas autoras deste manuscrito, com base na Classificação Internacional de Funcionalidade, Incapacidade e Saúde - CIF (ORGANIZAÇÃO... 2008) e na Estrutura da Prática da Terapia Ocupacional: domínio e processo (AMERICAN..., 2015). 